\title{
Investigating the Effect of Curing in the Chloride Diffusion Coefficient of Conventional Concrete
}

\author{
Aline Tabarelli ${ }^{a}$ Estela Oliari Garcez ${ }^{b}{ }^{\circledR}$, Francine Machado Nunes $^{a}{ }^{\circledR}$, Camila Monteiro Cholant $^{a}$, \\ Sofia Brand Scheibler ${ }^{c}$, César Oropesa Avellaneda ${ }^{a, *}$ \\ ${ }^{a}$ Centro de Desenvolvimento Tecnológico, Universidade Federal de Pelotas, Rua Gomes Carneiro, 1, \\ 96010-610, Pelotas, RS, Brasil \\ ${ }^{b}$ Deakin University, 75 Pigdons Rd, Waurn Ponds VIC 3216, Australia \\ ${ }^{c}$ Faculdade Anhanguera, Av. Fernando Osório, 2301, 96055-005, Pelotas, RS, Brasil
}

Received: February 21, 2019; Revised: June 15, 2019; Accepted: July 27, 2019

\begin{abstract}
Concrete is the most used material in the construction industry worldwide. Built concrete infrastructure is exposed to specific environments conditions during the asset's life, which impose chemical and physical actions that may lead to premature deterioration. Poor concrete durability and corrosion of reinforcement bars are the primary cause of structural deterioration and reduced service life. Most concrete deterioration mechanisms are driven by transport properties, in particular, the chloride diffusion coefficient. In this paper, the effect of curing in the chloride diffusion coefficient of conventional concrete is investigated through Electrochemical Impedance Spectroscopy (EIS). Reinforced concrete samples cured for 3, 7 and 28 days were exposed to accelerated chloride testing for 300 days (40 wet-dry cycles). Results indicate that the chloride diffusion coefficient reduces significantly with curing time, evidencing that prolonged curing may decrease the likelihood of corrosion in reinforced concrete structure when combined with appropriate design and construction processes.
\end{abstract}

Keywords: concrete, electrochemical techniques, durability, chloride diffusion coefficient.

\section{Introduction}

Cementitious materials are ancient building materials and have contributed to the reputation that concrete is a durable material. Over the centuries, cement compounds have evolved, and the invention of Portland cement in 1824 has revolutionized the construction industry. Concrete became the most utilized construction material worldwide, with annual demand approaching 30 billion metric tons ${ }^{1}$. Built infrastructure is vast and sustains our quality of life (buildings, transport infrastructure, bridges, airports, railways, and ports) and provide for our wellbeing (energy generation and distribution, water and wastewater storage facilities).

Designing optimized infrastructure (material choice, processes) and ensuring that concrete infrastructure performs to its specifications is of more critical importance now than ever. ${ }^{2}$

Reinforced concrete structures are prone to corrosion when exposed to severe conditions such as marine environments ${ }^{3}$. The corrosion process induced by chloride ions is the most common cause of structural deterioration and loss of concrete durability, causing substantial economic losses in terms of maintenance and repair costs ${ }^{4}$. The corrosion initiation period is affected by the critical concentration of chloride and by concrete cover, at the same time that the porosity of the cement paste directly influences the concrete diffusivity ${ }^{5}$. Prediction models are available in the literature ${ }^{6,7}$ to assist engineers and scientists in predicting the performance of reinforced concrete structures exposed to the aggressive marine environment ${ }^{8}$.
These prediction models rely on the chloride diffusion coefficient and the critical corrosion content;

Generally, the calculated diffusion parameters do not take into account the concrete age. However, the apparent diffusion coefficient changes over time, depending on the age and refinement of the concrete pore structure ${ }^{5}$. The continuous cement hydration changes the microstructure of the cement paste and contributes to the reduction of the penetration rate of chloride ions in prolonged periods of time ${ }^{9}$. Therefore, time-dependent properties should be considered in the evaluation and prediction of the durability of concrete structures ${ }^{10}$.

Electrochemical impedance spectroscopy (EIS) is traditionally used to characterize ionic transport and electrochemical reactions ${ }^{11}$. This technique can be used to predict the electrical properties of reinforced concrete during the curing process and when exposed to chloride ions, assisting on the determination of the corrosion potential and the polarization resistance of the steel rebar $(\text { electrode })^{12}$.

Impedance measurement employs alternating smallamplitude (AC) signals over a wide frequency range as a disturbance. Experimental data are often plotted in a complex plane known as the Nyquist diagram, which represents the real and the imaginary impedance components. The Nyquist diagram consists of a series of points, and each point represents the magnitude and direction of the impedance vector of a particular frequency ${ }^{13}$. 
From the diagram, the polarization resistance and solution resistance $\left(\mathrm{R}_{\mathrm{p}}\right.$ and $\left.\mathrm{R}_{\mathrm{s}}\right)$, the capacitance of the electrical double layer $\left(\mathrm{C}_{\mathrm{d}}\right)$ or the constant phase element $(\mathrm{CPE})$ and the diffusion or Warburg coefficient $\left(Z_{w}\right)$ can be obtained. With these parameters, series of material properties related to corrosion and durability can be determined. The kinetic reactions and diffusion are characterized by Faradaic impedance $Z_{F}$, with the Warburg impedance $Z_{\mathrm{w}}$ describing the diffusion behavior ${ }^{14,15}$.

From the Nyquist diagram, plotted as $Z=Z$ ' $i+Z$ ', the total impedance can be calculated by Equation $1^{14}$.

$$
Z=R_{S}+\frac{Z_{F}}{1+i \omega Z_{F} C_{d}}
$$

where $Z_{F}$ is the Faradaic impedance calculated by, $Z_{F}=R_{c t}+Z_{w}$, $Z_{\mathrm{w}}$ is the Warburg impedance calculated by $Z_{w}=\sigma_{W} \omega^{-\frac{1}{2}}(1-i)$, $\sigma_{\mathrm{W}}$ is the Warburg coefficient, $\mathrm{R}_{\mathrm{s}}$ is the electrolytic solution resistance, $\omega$ is the angular frequency, $R_{c t}$ is the charge transfer resistance, and $\mathrm{C}_{\mathrm{d}}$ is the capacitance of the electrode/ electrolyte interface.

In the most corrosive processes involving a double electric layer, $\lim _{\omega \rightarrow 0} \mathrm{Z}_{\mathrm{F}}=\mathrm{R}_{\mathrm{p}}$, with $\mathrm{R}_{\mathrm{p}}$ being the the polarization resistance proposed by Stern ${ }^{16}$.

The Warburg coefficient $\left(\sigma_{\mathrm{W}}\right)$ is related to the chloride diffusion coefficient(D) using Equation 2, for a reversible reaction $R_{c t} \rightarrow 0^{17}$.

$$
\sigma_{\mathrm{w}}=\frac{\mathrm{RT}}{\mathrm{F}^{2} \mathrm{~A} \sqrt{2} \mathrm{D}^{1 / 2} \mathrm{C}}
$$

where $\mathrm{R}$ is the gas constant, $\mathrm{T}$ is the absolute temperature, $\mathrm{F}$ is the Faraday constant, A is the surface area of the electrode, and $\mathrm{C}$ is chloride concentration.

The diffusion coefficient is calculated using Equation $3^{18}$ :

$$
D=\left[\frac{R T}{\sqrt{2} A F^{2} \sigma_{W} C}\right]^{2}
$$

where $\mathrm{D}$ is the diffusion coefficient of the chloride in $\mathrm{m}^{2} \mathrm{~s}^{-1}$. The coefficient $\sigma_{W}$ can be expressed in terms of admittance $\mathrm{Y}_{\mathrm{o}}$ through Equation 4.

$$
\sigma_{W}=1 /\left(Y_{O} .2^{1 / 2}\right)
$$

and rewritten in terms of the impedance $Z_{\mathrm{w}}$ (Equation 5) expressed in $\Omega^{-1} \mathrm{~s}^{1 / 2}$.

$$
\left|Z_{W}\right|=1 / Y_{O} \omega^{1 / 2}
$$

Low $\mathrm{Y}_{\mathrm{o}}$ values imply high impedance $\mathrm{Z}_{\mathrm{w}}$ and high Warburg conductivity. Since is inversely proportional to the diffusion coefficient $\mathrm{D}$, high $\sigma_{w}$ values are desirable for higher corrosion resistance ${ }^{19}$.

In order to monitor the diffusional behavior and transport of chloride ions over time, this work investigates the performance of reinforced concrete specimens cured for 3, 7 and 28 day, and exposed to saline environment using accelerated techniques for over 300 days. The apparent diffusion coefficient (D) was calculated using the Warburg impedance.

\section{Materials and Methods}

\subsection{Materials}

The materials used in the production of conventional concrete (CC) were high-early strength Brazilian Portland cement (CP V-ARI), two types of granite coarse aggregate and quartz sand, and water. No additives nor admixtures were added to the concrete. CP V-ARI contains higher clinker content and a higher fineness compared to general purpose cement, resulting in higher early strength, being largely used in precast applications. One batch of conventional concrete was used to prepare all samples investigated in this work. Table 1 presents the properties of materials used for concrete production. The concrete was mixed according to the Brazilian Standard ABNT NBR 12655: 2015². The mix proportion is shown in Table 2 .

\subsection{Methods}

Concrete cylinders (100 mm diameter and 200mm height) were cast according to the Brazilian Standard ABNT NBR 5738: $2016^{21}$, for the evaluation of compressive strength and impedance measurements. Cylinders were demolded after 24 hours of casting and samples were cured in calcium hydroxide saturated solution at $23 \pm 2^{\circ} \mathrm{C}$.

\subsubsection{Compressive strength}

The concrete compressive strength was evaluated according to the Brazilian Standard ABNT NBR 5739: 201822. The compressive strength was evaluated at 3, 7, 28 and 91 days of curing. Three cylinders were tested at each curing age.

Table 1. Properties of materials used the production of concrete.

\begin{tabular}{lcccc}
\hline Properties & Portland CPV High Early Strength Cement & Gravel 0 Stone & Gravel 1 Stone & Sand \\
\hline Specific Mass $\left(\mathrm{g} / \mathrm{cm}^{3}\right)$ & 3.21 & 2.65 & 2.66 & 2.604 \\
Unitary Mass $\left(\mathrm{g} / \mathrm{cm}^{3}\right)$ & - & 1.35 & 1.51 & 1.548 \\
Index of Voids $(\%)$ & - & 48.68 & 42.0 & - \\
Maximum Diameter $(\mathrm{mm})$ & - & 9.50 & 19 & 1.18 \\
\hline
\end{tabular}

Table 2. Concrete Mix Proportions in $\mathrm{kg} / \mathrm{m}^{3}$.

\begin{tabular}{ccccccc}
\hline Mix & w/c ratio & Water & Cement & Sand & Gravel 0 & Gravel 1 \\
\hline CC & 0.5 & 191.3 & 382.6 & 733.6 & 321.7 & 750.7 \\
\hline
\end{tabular}




\subsubsection{Electrochemical impedance spectroscopy}

Figure 1 shows the sample used for the electrochemical analysis. The cylinders were cast with the insertion of an $8 \mathrm{~mm}$ steel rebar electrode and an inert graphite electrode of $8 \mathrm{~mm}$. The steel bar is classified as CA-50, with $500 \mathrm{MPa}$ tensile strength. The rebar was placed with a $40 \mathrm{~mm}$ cover against the lateral surface, as this is the minimum cover recommended for aggressive marine environment ${ }^{23}$. The spacing between the steel bar and the graphite electrode was $20 \mathrm{~mm}$.

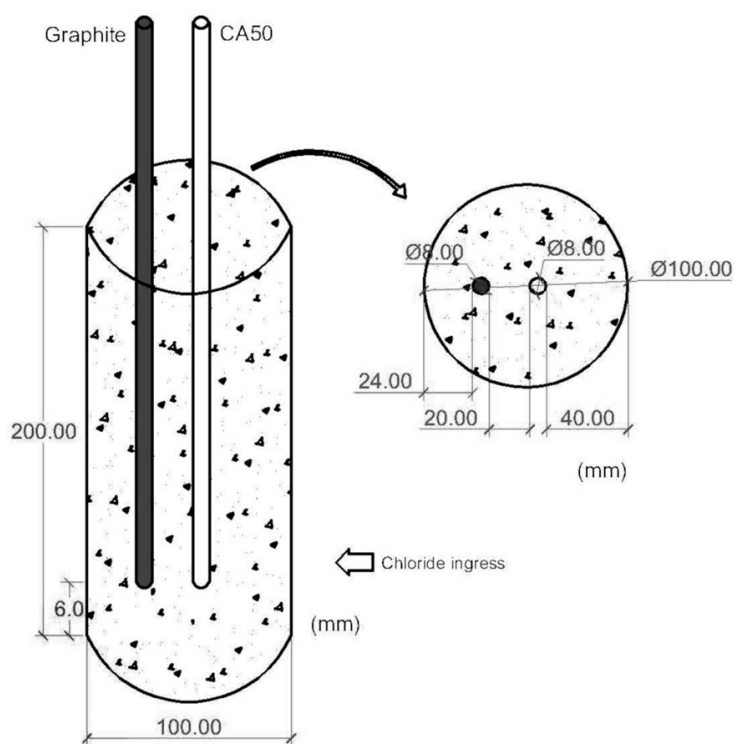

Figure 1. Samples used for the electrochemical impedance analysis.

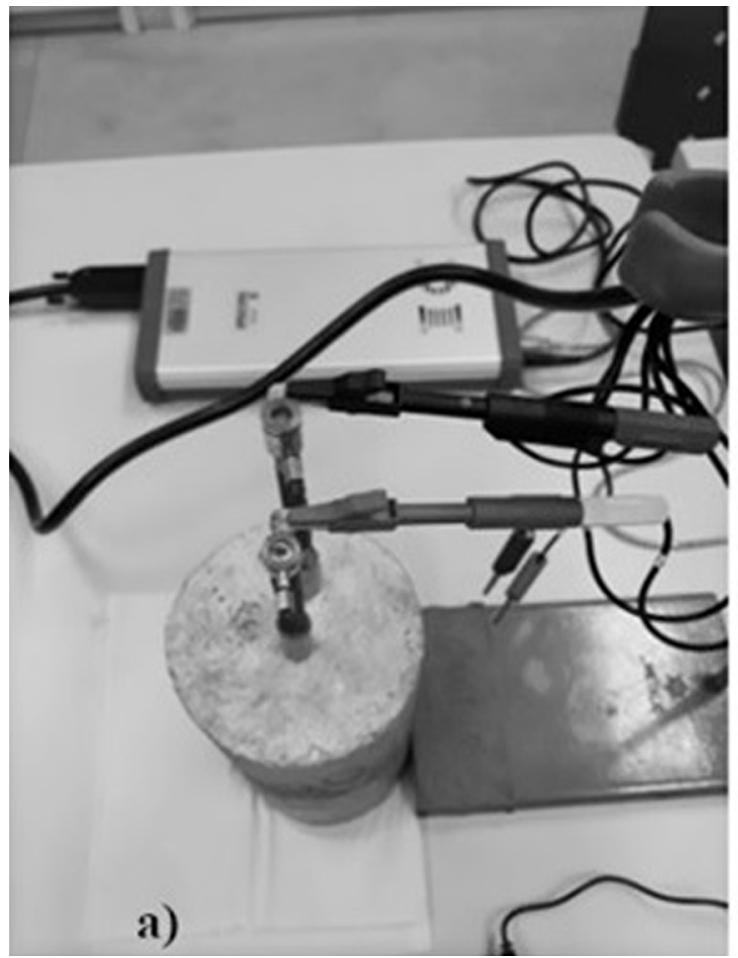

Three different curing period were investigated: 3,7 and 28 days. Six samples were cast for each curing age. Samples were submerged in calcium hydroxide solution for the chosen curing time and then transferred to a saline solution tank, with a $3.5 \%$ sodium chloride $(\mathrm{NaCl})$ solution. Alternate dry and wet cycles were performed to accelerate the corrosion process of embedded steel rebar, previously used in other corrosion studies ${ }^{10,24-29}$. One cycle consisted of 5 days under drying condition (exposed in air, laboratory environment) and 2 days under wetting condition (tank with $\mathrm{NaCl}$ solution).

Impedance measurements were performed using an IVIUM STAT Potentiostat/Galvanostat, applying an alternating signal with a $25 \mathrm{mV}$ for a frequency range from 0.05 to $10^{6}$ $\mathrm{Hz}$. For the EIS measurements, the volumetric measurement was adopted, considering the ingression of chloride ions in all directions (Figure 2).

\subsubsection{Chloride Penetration}

Chloride penetration is known to be time-dependent, and the penetration also affects the apparent diffusion coefficient $\mathrm{D}$, due of the retarding effect on the diffusion process as a result of chloride binding and refinement of the concrete pore structure over time ${ }^{10}$. The penetration of chloride and its transport rate throughout concrete are also largely dependent on the characteristics of cement paste, in terms of concrete pore structure, concrete mixing ratio, conditions of cure and exposure ${ }^{30}$. After 40 drying and wetting cycles, a concrete sample cured for 28-days was broken in two halves and submitted to the $\mathrm{AgNO}_{3}$ spray test ${ }^{31}$. This test was carried out to quantify the penetration depth with extended exposure to the chloride solution.

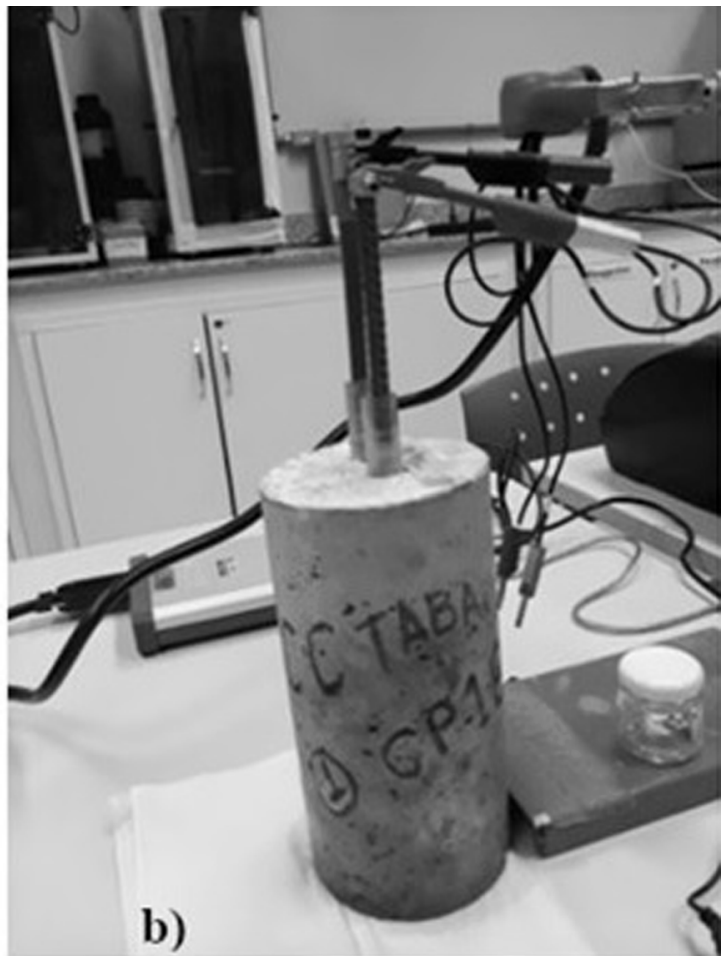

Figure 2. Electrochemical measurements - cylindrical concrete blocks, (a) upper view and (b) front view. 
As the chloride penetration is not uniform, the NT BUILD $492^{32}$ recommends taking measurements every $1 \mathrm{~cm}$, with the result being the average of all measurements.

\subsubsection{Scanning electron microscopy (SEM)}

The morphology of the concrete specimens cured for 28 days (before and after the chloride penetration test) was evaluated by scanning electron microscopy, using a JSM-6610 LV Scanning Electron Microscope by JEOL, at CEME-SUL Laboratory/Brazil.

\section{Results and Discussion}

\subsection{Compressive strength}

The average concrete compressive strength and standard deviation at different curing time are shown in Table 3. The average compressive strength at 28 days is $42.38 \mathrm{MPa}$, which falls within the recommended compressive strength for reinforced concrete structures exposed to marine environment ${ }^{23}$.

\subsection{Electrochemical impedance spectroscopy}

\subsubsection{Nyquist Diagram}

In order to analyze the corrosion process of the steel rebar, EIS measurements were carried out as a function of time. Figure 3, 4 and 5 shows the Nyquist plots starting from the initial measurement after the 3, 7 and 28-day curing period, respectively, and ending after 40 cycles, which represents 300 days of continuous monitoring. The curves show the average of six samples measured for each curing time. The electrical resistivity gives insights on the concrete microstructure and durability, as the resistivity indicates how much the material controls the movement of free electrons 9 . The frequencies related to maximum impedance and the initial diffusion process are indicated in the Figures 3 to 5 . The frequencies did not change for the different curing times over the 40 wet and dry cycles. For the maximum impedance, the frequency was $709.6 \mathrm{kHz}$, and at the initial diffusion process, the frequency was $8.2 \mathrm{kHz}$.

Figures 3, 4 and 5 show a gradual increase of real impedance (Z') in the first 20 to 28 cycles, depending on the curing time, representing an increment in concrete resistivity, probably due to cement hydration processes and refinement of concrete microstructure. It is understood that the more porous the concrete and the more interconnected pores, the lower the electrical resistivity and, consequently, the higher the likelihood of corrosion?

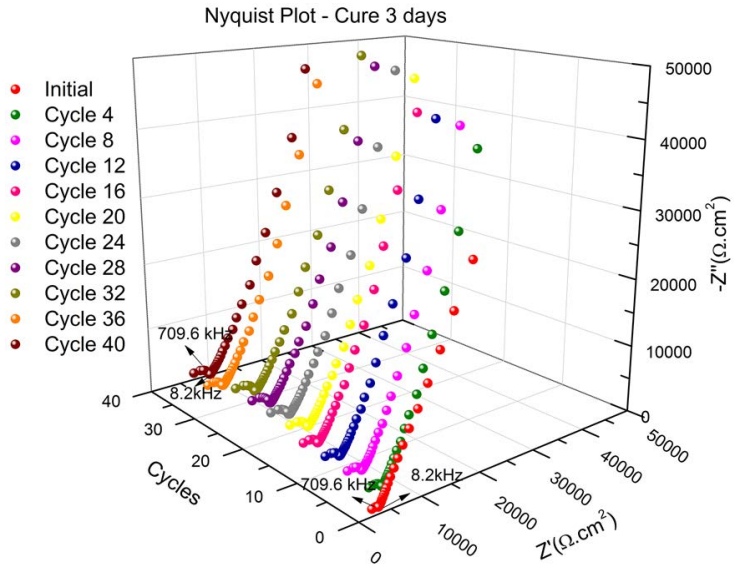

Figure 3. Nyquist Diagram - Cylindrical CC, cured for 3 days and submitted to 40 wetting and drying cycles.

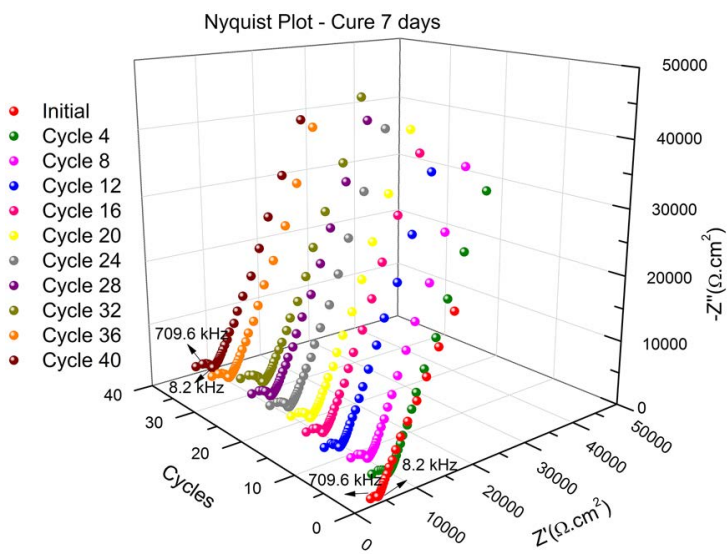

Figure 4. Nyquist Diagram - Cylindrical CC, cured for 7 days and submitted to 40 wetting and drying cycles.

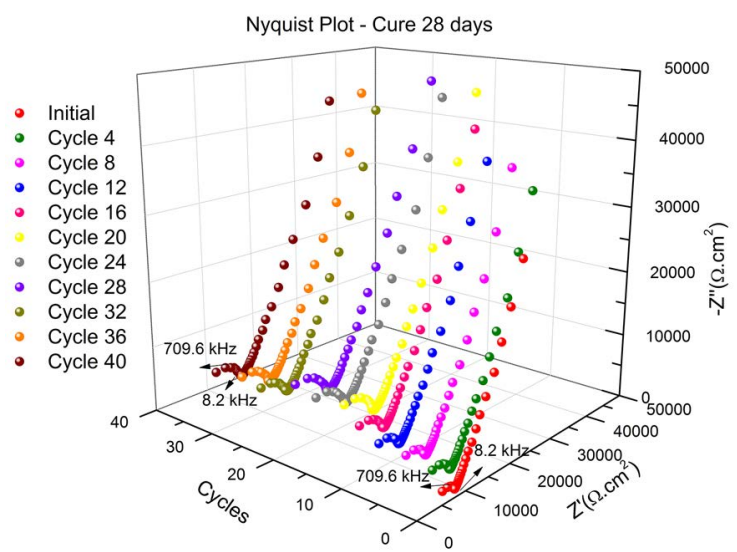

Figure 5. Nyquist Diagram - Cylindrical CC, cured for 28 days and submitted to 40 wetting and drying cycles.

Table 3. Compressive strength at the ages of 3, 7, 28 and 91 days.

\begin{tabular}{|c|c|c|c|c|}
\hline & 3 days $(\mathrm{MPa})$ & 7 days $(\mathrm{MPa})$ & 28 days $(\mathrm{MPa})$ & 91 days $(\mathrm{MPa})$ \\
\hline \multicolumn{5}{|l|}{ Average } \\
\hline Compressive & $29.39 \pm 3.66$ & $31.76 \pm 0.99$ & $42.38 \pm 1.26$ & $46.02 \pm 0.89$ \\
\hline Strength & & & & \\
\hline
\end{tabular}


After 32 cycles, for all curing ages, a slight and gradual decrease of the real impedance (Z') was observed, which represents higher conductivity. These results follow previous results reported in the literature ${ }^{33}$.

A significant increase in impedance (Z') was observed for the 28-day cured samples compared to 3 and 7-day curing. As seen in Table 3, the compressive strength of 3-day (29.39 $\mathrm{MPa})$ and 7 -day cured samples $(31.76 \mathrm{MPa})$ are very similar, possibly indicating similar concrete microstructure at both ages. This similarity is also reflected in the impedance of the 3-day and 7-day cured samples, as seen in the Nyquist diagrams (Figure 3 and 4). At 28-day curing, the concrete compressive strength is $42.38 \mathrm{MPa}$, which is $33 \%$ higher than the compressive strength at 7-day. As the compressive strength increases, the impedance also increases, as seen in Figure 5.

\subsubsection{Equivalent circuit model}

John et al. ${ }^{34}$ proposed a circuit for measuring corrosion in reinforced concrete samples, where the impedance at low-frequency responses is related to the charge transfer process, and at high- frequency is attributed to the presence of a surface film. The equivalent circuit used in this work is shown in Figure 6, following the model $[\mathrm{R}(\mathrm{QR})([\mathrm{RW}] \mathrm{Q})]^{18,34,35}$. The circuit introduces the constant phase element (CPE) in the equivalent circuits, which leads to an increased accuracy when compared to ideal capacitors ${ }^{36}$. The layers model includes the electrolyte resistance $R_{e}$, the constant phase element $\mathrm{CPE}_{\mathrm{C}}$ and resistance $\mathrm{R}_{\mathrm{C}}$ of concrete, the $\mathrm{CPE}_{\mathrm{S}}$ and $\mathrm{R}_{\mathrm{S}}$ of the oxide layer on the steel bar, and the Warburg impedance $Z_{w}$.

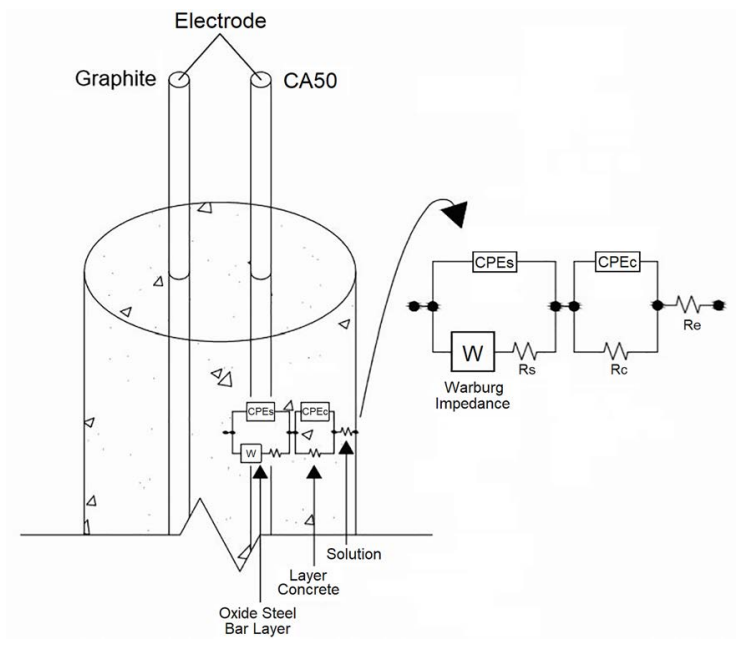

Figure 6. Equivalent Circuit Model $[\mathrm{R}(\mathrm{QR})([\mathrm{RW}] \mathrm{Q})]$.
The Nyquist diagrams were analyzed by the proposed equivalent circuit shown in Figure 6. The fitting curves shown in Figure 7 demonstrate that the equivalent circuit was able to represent the impedance of the steel-concrete system accurately.

The resistance R, constant phase element $\mathrm{CPE}$ and admittance Yo of the samples cured for 3, 7 and 28-day, for 4 cycles are shown in Table 4, using the simplified equivalent circuit [R(RQ) (RQ)]. Results show that the concrete resistance increased $34 \%$ from 3-day to 28-day curing in the first 4 cycles, with a decrease in the CPE from $4.88 \times 10^{-8}$ to $4.80 \times 10^{-9} \mathrm{~F}^{-\mathrm{cm}^{-2}}$, probably due to the higher density of the hydration products and the refined pore microstructure of the 28-day cured concrete samples. Bragança et al. ${ }^{37}$ reported similar behavior, with a decrease in capacitance from $10^{-8} \mathrm{~F}^{-\mathrm{cm}^{-2}}$ at 28-day to $1,5 \times 10^{-9} \mathrm{~F}_{\mathrm{cm}} \mathrm{cm}^{-2}$ at 264-day.

Also, the electrolyte resistance doubled at 28-day compared to 3-day, due to the refinement pore size, distribution, and tortuosity of capillary pores and chemical interactions between adsorbed ions and cement compounds ${ }^{38}$.

The resistance of the oxide film formed on the steel bar was $1.10 \mathrm{~T} \Omega . \mathrm{cm}^{2}$, with a non-ideal capacitance of $8.77 \times 10^{-5} \mathrm{~F}_{\mathrm{cm}} \mathrm{cm}^{2}$. The $\mathrm{CPE}_{\mathrm{S}}$ remained stable for all curing times, indicating no damage to the protective oxide film on the steel bar up to cycle 4 , as expected for a limited exposure time.

\subsubsection{Polarization resistance ( $R p)$}

The results of average polarization resistances are presented in Figures 8, 9 and 10 for 3, 7 and 28-day curing, respectively, with error bars, demonstrating the concrete resistive behavior over 40 cycles.

Figure 8, 9 e 10 shows an increase in the concrete polarization resistance $\mathrm{R}_{\mathrm{p}}$ over time as a general trend. It was observed that, for the 3-day and 7-day curing, the $R_{p}$ values are similar from cycle 2 to 18 , with no significant variation. For the 28-day curing, the same trend is observed; however the $\mathrm{R}_{\mathrm{p}}$ values are higher compared to the 3 and 7-day. The same trend was reported by Sabbag and Uyanik in their studies with reinforced concrete samples after 100 days of exposure ${ }^{39}$. At the end of cycle 40, a reduction in the Rp was observed, due to the exposure to chloride ions and the process of degradation of the material, as previously explained.

Figure 11 shows the comparison of $R_{p}$ values at 3, 7 and 28 -day curing. There is a $10 \%$ increase in the polarization resistance $\mathrm{R}_{\mathrm{p}}$ from 3-day to 7-day curing, and an increase of $40 \%$ from 7 to 28 -day curing.

Diffusion coefficient $\mathrm{D}$ calculated from the coefficient of Warburg impedance

Table 4. The resistance R, constant phase element CPE and admittance $Y_{o}$ of the equivalent circuit components for samples cured at 3,7 and 28 days

\begin{tabular}{ccccccccc}
\hline Cycle & Curing time & $\mathrm{R}_{\mathrm{e}} \mathrm{k} \Omega . \mathrm{cm}^{2}$ & $\mathrm{R}_{\mathrm{C}} \mathrm{k} \Omega . \mathrm{cm}^{2}$ & Yos, $\mathrm{n} 1 \mu$ Mho & $\mathrm{CPE}_{\mathrm{C}}{\mathrm{F} . \mathrm{cm}^{-2}}$ & $\mathrm{R}_{\mathrm{S}} \mathrm{T} \Omega . \mathrm{cm}^{2}$ & $\mathrm{Yo}_{\mathrm{S}}, \mathrm{n} 2 \mu$ Mho & CPES F.cm $^{-2}$ \\
\hline \multirow{4}{*}{4} & 3-day & 4.06 & 3.73 & $24.4 \mathrm{n}=0.5$ & $4.88 \times 10^{-8}$ & 1.10 & $57.9 \mathrm{n}=0.66$ & $8.77 \times 10^{-5}$ \\
& 7-day & 5.26 & 4.37 & $9.41 \mathrm{n}=0.621$ & $1.07 \times 10^{-8}$ & 1.10 & $59.8 \mathrm{n}=0.702$ & $8.52 \times 10^{-5}$ \\
& 28-day & 8.37 & 5.03 & $3.32 \mathrm{n}=0.691$ & $4.80 \times 10^{-9}$ & 1.10 & $57.7 \mathrm{n}=0.614$ & $9.40 \times 10^{-5}$ \\
\hline
\end{tabular}



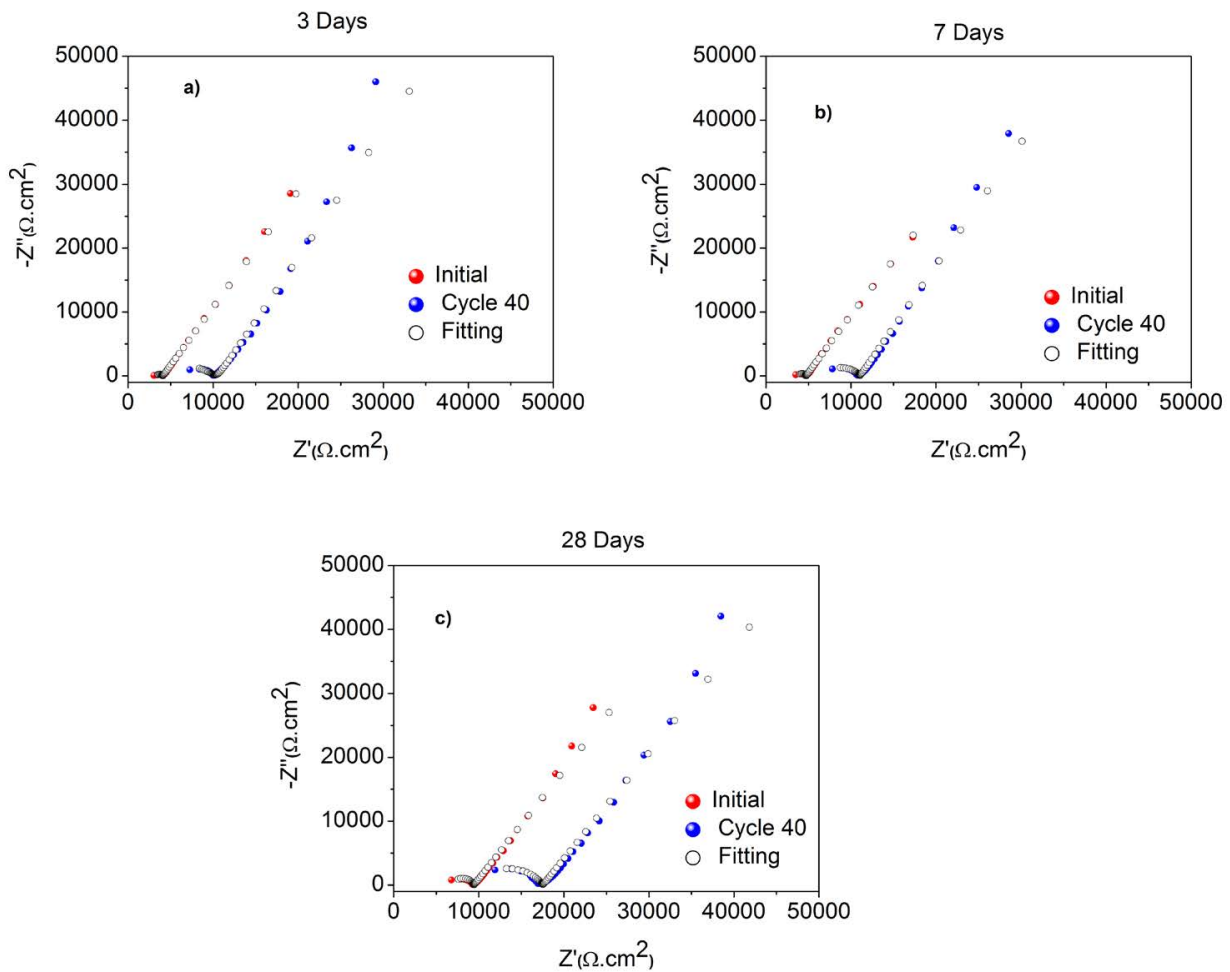

Figure 7. Electrochemical impedance curves - Nyquist Diagram - Fitting, (a) 3 days, (b) 7 days and (c) 28 days curing.

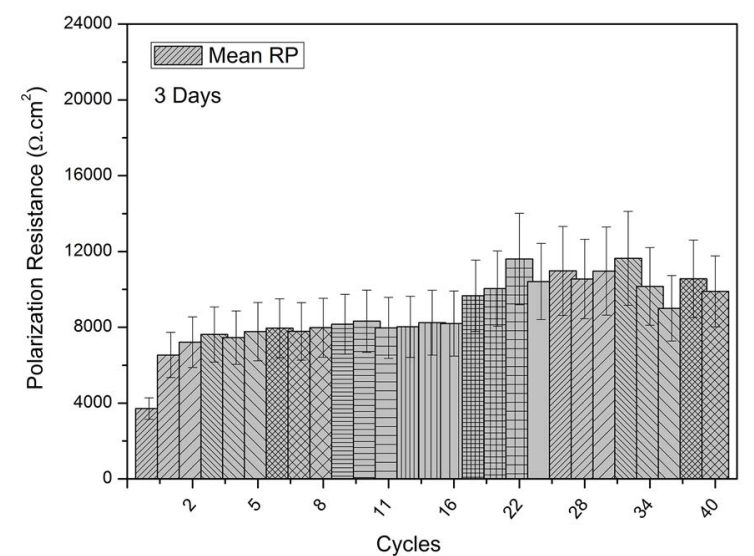

Figure 8. $R_{p}$ column graphs for 3 days.

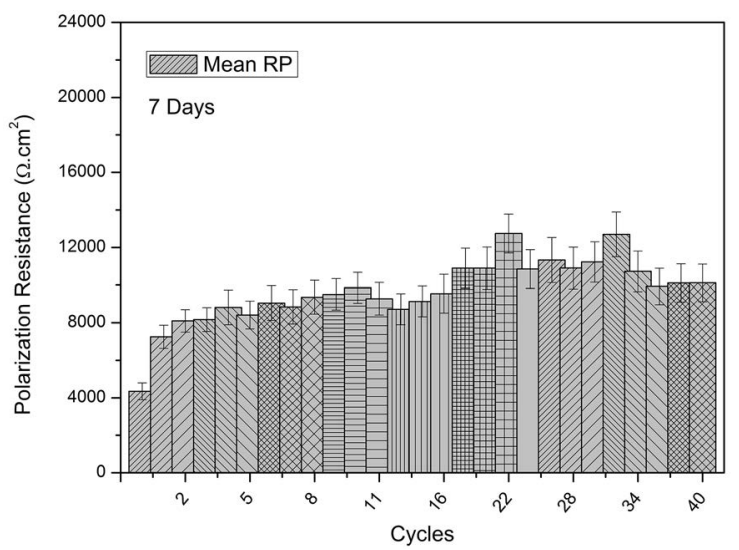

Figure 9. $R_{p}$ column graphs for 7 days.

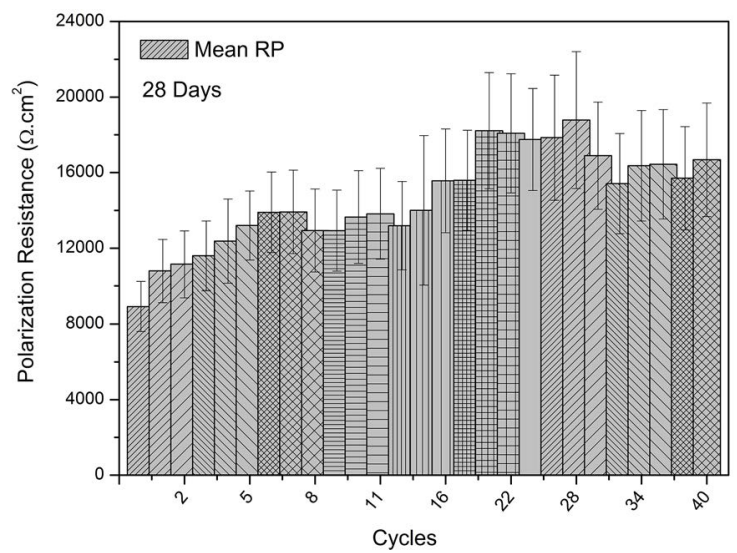

Figure 10. $R_{p}$ column graphs for 28 days.

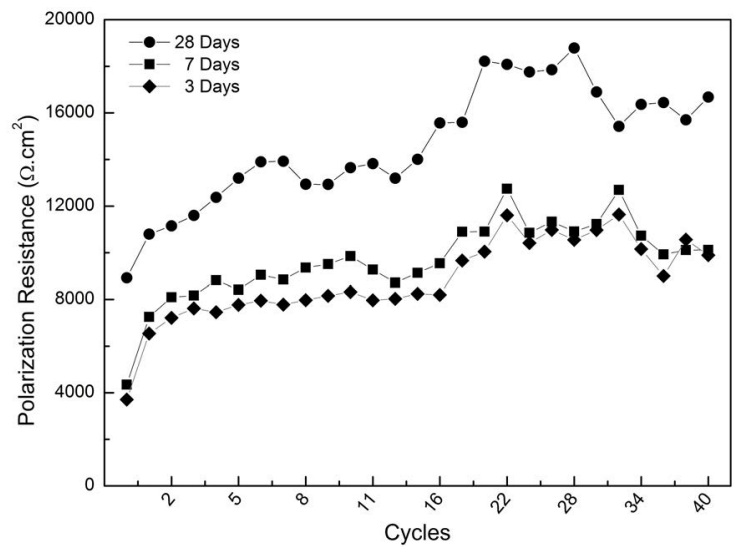

Figure 11. Comparative plots of $R_{p}$ for 3, 7 and 28-day curing. 
The diffusion coefficient $\mathrm{D}$ was calculated using the impedance of Warburg, where the coefficient was calculated in terms of admittance $Y_{0}$. Figure 12 shows the diffusion coefficient of Warburg for the different curing period based on the mean $R_{p}$ values, using Equations 3 and 5, where the Warburg impedance is a constant phase element for a phase angle of $45^{\circ}$.

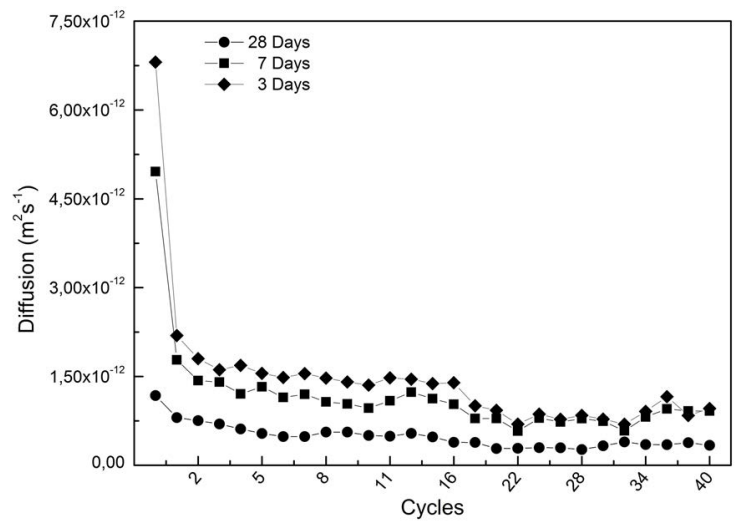

Figure 12. Warburg diffusion for different curing times.

The diffusion coefficient at cycle 1 were $6.8 \times 10^{-12}, 4.9 \times 10^{-12}$, and $1.17 \times 10^{-12} \mathrm{~m}^{2} / \mathrm{s}$ for the 3,7 and 28 -day curing, respectively. The 3-day curing samples showed a higher diffusion coefficient, indicating a higher probability of corrosion. At 300 days (40 cycles), the diffusion coefficient were $0.9 \times 10^{-12}, 0.7 \times 10^{-12}$ and $0.3 \times 10^{-12} \mathrm{~m}^{2} / \mathrm{s}$, for samples cured for 3,7 and 28 -day, respectively. The diffusion coefficient of 3-day cured samples was, therefore, three times higher than the 28-day cured samples.

A reduction in the diffusion coefficient was observed for all curing times throughout the cycles. However, the reduction was not as significant for the samples cured for 28-day, as the initial diffusion coefficient was already low due to the extended cure before the exposure to the first cycle, evidencing the importance of curing in preventing the ingression and transport of chlorides in early ages. Similar results were reported by $\mathrm{Wu}$ et al. ${ }^{10}$ for concrete samples exposed to natural marine environment in the Gulf of Beibu, China, with a diffusion coefficient of $1.18 \times 10^{-12} \mathrm{~m}^{2} / \mathrm{s}, 1.01 \times 10^{-12} \mathrm{~m}^{2} / \mathrm{s}$ and $0.83 \times 10^{-12} \mathrm{~m}^{2} / \mathrm{s}$ for an exposure period of 35, 62 and 80 months. It is clear from the results that the 28-day cured concrete can delay the diffusion processes, demonstrating the benefits of extended curing for more durable concrete structures.

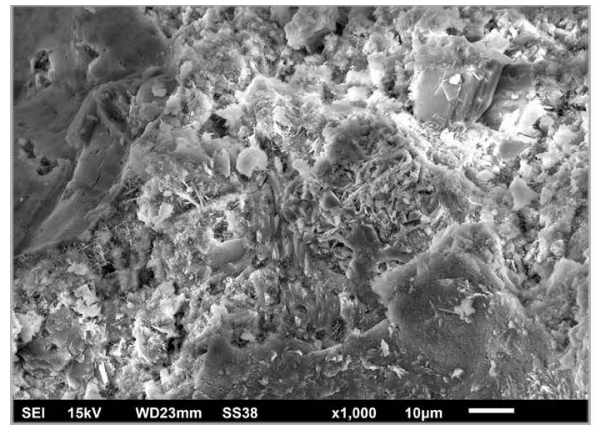

\subsection{Chloride penetration}

Figure 13 shows the presence of chlorides in the 28-day cured sample after the $\mathrm{AgNO}_{3}$ spray test. The light grey area shows the chloride penetration depth and the brown are shows the chloride free zone. The chloride penetration depth found after 40 cycles was $21.1 \mathrm{~mm}$. The results confirm the ingression of chlorides ions in the sample. Note that for some steel reinforced concrete components, such as slabs, the minimum recommended cover is $20 \mathrm{~mm}$, which means only after 40 cycles, the chloride ions would have reached the bars and the corrosion processes would have been initiated.

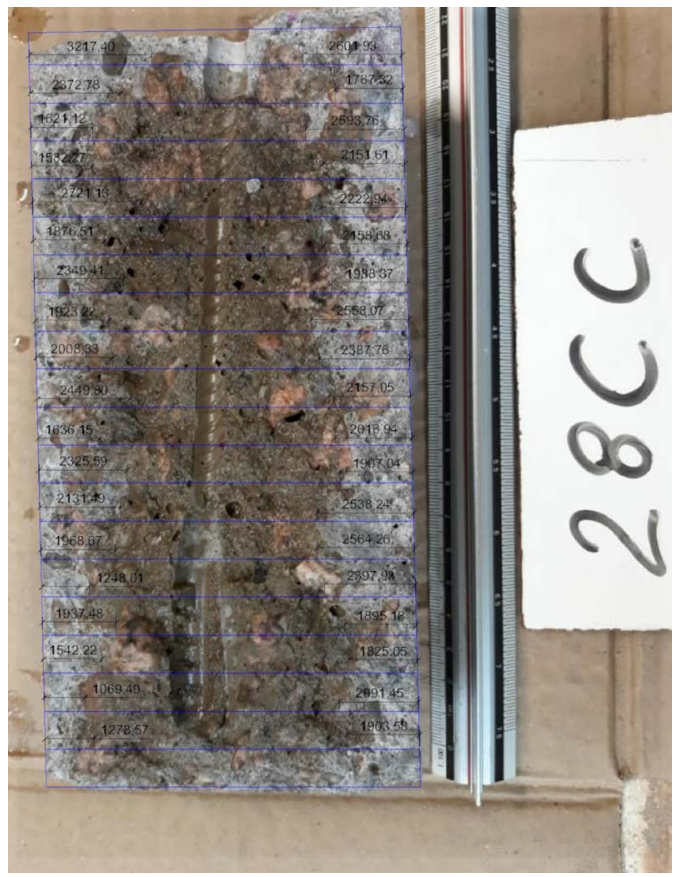

Figure 13. Chloride Penetration of samples with 28-day curing for 40 cycles.

\subsection{Scanning electron microscopy (SEM)}

Figure 14 shows the SEM images of the concrete sample cured for 28-day and the sample after the exposure to 40 cycles. The concrete microstructure is denser after 40 cycles, indicating improved pore refinement and lower number of interconnected pores.

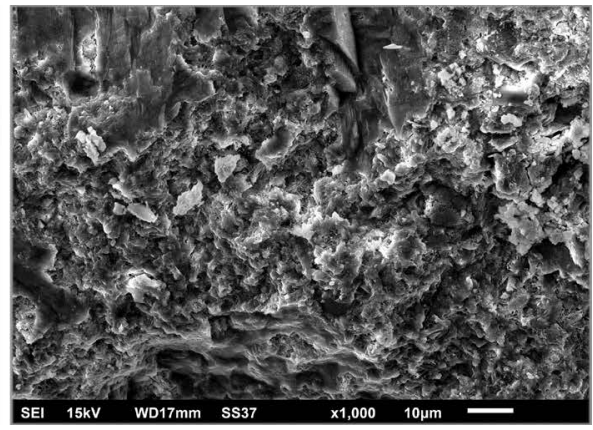

Figure 14. Morphology of samples of concrete cured for 28 days (left) and after the exposure to 40 cycles (right). 


\section{CONCLUSION}

Based on the results presented in this paper, the main findings are as follow.

The polarization resistance $\left(\mathrm{R}_{\mathrm{p}}\right)$ of concrete samples cured for 3 and 7-day was very similar throughout the first 40 wetting and drying cycles. Significant differences were found only for the concrete samples cured for 28 days. The results showed that, for all curing times, there is an initial increase in the polarization resistance $\left(\mathrm{R}_{\mathrm{p}}\right)$, followed by a decrease after 32 cycles. This behavior might be related to the ingress of chloride ions and the initiation of deterioration processes in the material. The polarization resistance of conventional concrete over further exposure (beyond 40 cycles) is under investigation in order to effectively evaluate the changes observed after 32 cycles.

The samples cured for 28 days have lower diffusion coefficient throughout the 40 cycles compared to 3 and 7-day curing, highlighting the importance of extended and proper curing on the durability of conventional concrete structures.

\section{ACKNOWLEDGEMENTS}

We want to thank the LAFFIMAT (Laboratório de Filmes Finos e Novos Materiais) at Federal University of Pelotas, Brazil, for allowing us to use their facilities to undertake this research and for funding the research. We also would like to thank the CEME-SUL (Centro de Microscopia Eletrônica do Sul) at Federal University do Rio Grande, Brazil.

\section{REFERENCES}

1. Vázquez-Rowe I, Ziegler-Rodriguez K, Laso J, Quispe I, Aldaco R, Kahhat R. Production of cement in Peru: Understanding carbonrelated environmental impacts and their policy implications. Resources, Conservation and Recycling. 2019;142:283-292.

2. Gardoni P, Murphy C. Society-based design: promoting societal well-being by designing sustainable and resilient infrastructure. Sustainable and Resilient Infrastructure. 2018;1-16.

3. van den Heede P, van Belleghem B, Araújo MA, Feiteira J, de Belie N. Screening of Different Encapsulated Polymer-Based Healing Agents for Chloride Exposed Self-Healing Concrete Using Chloride Migration Tests. Key Engineering Materials. 2018;761:152-158.

4. van Zijl GPAG, Paul SC. A novel link of the time scale in accelerated chloride-induced corrosion test in reinforced SHCC. Construction and Building Materials. 2018;167:15-19.

5. Luping T, Gulikers J. On the mathematics of time-dependent apparent chloride diffusion coefficient in concrete. Cement and Concrete Research. 2007;37(4):589-595.

6. Tang L, Nilsson LO, Basheer PAM. Resistance of Concrete to Chloride Ingress: Testing and Modelling. London: Spon Press; 2012.

7. Collepardi M, Marcialis A, Turriziani R. Penetration of Chloride Ions into Cement Pastes and Concretes. Journal of the American Ceramic Society. 1972;55(10):534-535.
8. Li K, Zhang D, Li Q, Fan Z. Durability for concrete structures in marine environments of HZM project: Design, assessment and beyond. Cement and Concrete Research. 2019;115:545-558.

9. Metha PK, Monteiro PJM. Concrete: Microstructure, Properties, and Materials. New York: McGraw-Hill Education; 2014.

10. Wu L, Li W, Yu X. Time-dependent chloride penetration in concrete in marine environments. Construction and Building Materials. 2017;152:406-413.

11. Peng W, Aranda C, Bakr OM, Garcia-Belmonte G, Bisquert J, Guerrero A. Quantification of Ionic Diffusion in Lead Halide Perovskite Single Crystals. ACS Energy Letters. 2018;3(7):14771481.

12. Macdonald JR. Impedance spectroscopy. Annals of Biomedical Engineering. 1992;20(3):289-305.

13. Ribeiro DV, Abrantes JCC. Application of electrochemical impedance spectroscopy (EIS) to monitor the corrosion of reinforced concrete: A new approach. Construction and Building Materials. 2016;111:98-104.

14. Shi M, Chen Z, Sun J. Determination of chloride diffusivity in concrete by AC impedance spectroscopy. Cement and Concrete Research. 1999;29(7):1111-1115.

15. Brosel Oliu S, Uria N, Abramova N, Bratov A. Impedimetric Sensors for Bacteria Detection. In: Rinken T, ed. Biosensors-Micro and Nanoscale Applications. London: IntechOpen; 2015. p. 257-288.

16. Aksüt AA, Lorenz WJ, Mansfeld F. The determination of corrosion rates by electrochemical d.c. and a.c. methods - II. Systems with discontinuous steady state polarization behavior. Corrosion Science. 1982;22(7):611-619.

17. Hu X, Shi C, De Schutter G. A review on microstructure characterization of cement-based materials subjected to chloride by AC Impedance. In: $4^{\text {th }}$ International Conference on Sustainable Construction Materials and Technologies (SCMT4); 2016 Aug 7-11; Las Vegas, NV, USA. Sustainable Construction Materials and Technologies; 2016. $11 \mathrm{p}$.

18. Vedalakshmi R, Saraswathy V, Song HW, Palaniswamy N. Determination of diffusion coefficient of chloride in concrete using Warburg diffusion coefficient. Corrosion Science. 2009;51(6):1299-1307.

19. Bayón R, Igartua A, González JJ, Ruiz de Gopegui U. Influence of the carbon content on the corrosion and tribocorrosion performance of Ti-DLC coatings for biomedical alloys. Tribology International. 2015;88:115-125.

20. Associação Brasileira de Normas Técnicas (ABNT) - Brazilian Standard. ABNT NBR 12655-2015 - Portland cement concrete - Preparation, control, receipt and acceptance - Procedure. Rio de Janeiro: ABNT; 2015.

21. Associação Brasileira de Normas Técnicas (ABNT) - Brazilian Standard.ABNTNBR 5738-2016-Concrete-Procedure for molding and curing concrete test specimens. Rio de Janeiro: ABNT; 2016.

22. Associação Brasileira de Normas Técnicas (ABNT) - Brazilian Standard. ABNT NBR 5739-2018 - Concrete - Compression test of cylindrical specimens. Rio de Janeiro: ABNT; 2018.

23. Associação Brasileira de Normas Técnicas (ABNT) - Brazilian Standard. ABNT NBR 6118-2014 - Design of concrete structures - Procedure. Rio de Janeiro: ABNT; 2014. 
24. Valipour M, Shekarchi M, Arezoumandi M. Chlorine diffusion resistivity of sustainable green concrete in harsh marine environments. Journal of Cleaner Production. 2017;142(Pt 4):4092-4100.

25. Wei Y, Guo W, Liang S. Chloride Ingress in Internally Cured Concrete under Complex Solution. Journal of Materials in Civil Engineering. 2018;30(4):04018037.

26. Triantafyllou GG, Rousakis TC, Karabinis AI. Effect of patch repair and strengthening with EBR and NSM CFRP laminates for $\mathrm{RC}$ beams with low, medium and heavy corrosion. Composites Part B: Engineering. 2018;133:101-111.

27. Medeiros MHF, Gobbi A, Réus GC, Helene P. Reinforced concrete in marine environment: Effect of wetting and drying cycles, height and positioning in relation to the sea shore. Construction and Building Materials. 2013;44:452-457.

28. Subbiah K, Velu S, Kwon SJ, Lee HS, Rethinam N, Park DJ. A novel in-situ corrosion monitoring electrode for reinforced concrete structures. Electrochimica Acta. 2018;259:1129-1144.

29. Angst UM, Elsener B, Larsen CK, Vennesland Ø. Chloride induced reinforcement corrosion: Electrochemical monitoring of initiation stage and chloride threshold values. Corrosion Science. 2011;53(4):1451-1464.

30. Pack SW, Jung MS, Song HW, Kim SH, Ann KY. Prediction of time dependent chloride transport in concrete structures exposed to a marine environment. Cement and Concrete Research. 2010;40(2):302-312.

31. Baroghel-Bouny V, Belin P, Maultzsch M, Henry D. $\mathrm{AgNO}_{3}$ spray tests: advantages, weaknesses, and various applications to quantify chloride ingress into concrete. Part 1: Non-steady-state diffusion tests and exposure to natural conditions. Materials and Structures. 2007;40(8):759.
32. Nordtest. NT BUILD 492. Concrete, mortar and cement-based repair materials: Chloride migration coefficient from non-steady state migration experiments. Espoo: Nordtest; 1999.

33. Karhunen K, Seppänen A, Lehikoinen A, Blunt J, Kaipio JP, Monteiro PJM. Electrical Resistance Tomography for Assessment of Cracks in Concrete. ACI Materials Journal. 2010;107(5):523-531.

34. John DG, Searson PC, Dawson JL. Use of AC Impedance Technique in Studies on Steel in Concrete in Immersed Conditions. British Corrosion Journal. 1981;16(2):102-106.

35. Ribeiro DV, Souza CAC, Abrantes JCC. Use of Electrochemical Impedance Spectroscopy (EIS) to monitoring the corrosion of reinforced concrete. Revista IBRACON de Estruturas $e$ Materiais. 2015;8(4):529-546.

36. Sagüés AA, Kranc SC, Moreno EI. The time-domain response of a corroding system with constant phase angle interfacial component: Application to steel in concrete. Corrosion Science. 1995;37(7):1097-1113.

37. Bragança MOGP, Portella KF, Bonato MM, Marino CEB. Electrochemical impedance behavior of mortar subjected to a sulfate environment - A comparison with chloride exposure models. Construction and Building Materials. 2014;68:650-658.

38. Gu P, Xie P, Beaudoin JJ, Brousseau R. A.C. Impedance spectroscopy (II): Microstructural characterization of hydrating cement-silica fume systems. Cement and Concrete Research. 1993;23(1):157-168.

39. Saraswathy V, Song HW. Electrochemical studies on the corrosion performance of steel embedded in activated fly ash blended concrete. Electrochimica Acta. 2006;51(22):4601-4611. 